\title{
Reliability and validity of a Dutch version of the Leicester Cough Questionnaire
}

\author{
Arnold N Huisman ${ }^{1}$, Mei-Zei Wu${ }^{1}$, Steven M Uil ${ }^{1}$ and Jan Willem K van den \\ Berg*1,2
}

\author{
Address: 'Department of Pulmonology, Isala klinieken, Postbus 10500, 8000 GM Zwolle, The Netherlands and ${ }^{2}$ University Medical Center \\ Groningen, University of Groningen, Groningen, the Netherlands \\ Email: Arnold N Huisman - a.n.huisman@isala.nl; Mei-Zei Wu - m.z.wu@isala.nl; Steven M Uil - s.m.uil@isala.nl; Jan Willem K van den \\ Berg* - j.w.k.van.den.berg@isala.nl \\ * Corresponding author
}

Published: 2I February 2007

Cough 2007, 3:3 doi:10.1186/1745-9974-3-3

This article is available from: http://www.coughjournal.com/content/3/l/3

(C) 2007 Huisman et al; licensee BioMed Central Ltd.

This is an Open Access article distributed under the terms of the Creative Commons Attribution License (http://creativecommons.org/licenses/by/2.0), which permits unrestricted use, distribution, and reproduction in any medium, provided the original work is properly cited.
Received: 10 November 2006

Accepted: 21 February 2007

\begin{abstract}
Background: Chronic cough is a common condition with a significant impact on quality of life. Currently, no health status measure specific for chronic cough exists in the Netherlands. Thus we developed a Dutch version of the Leicester Cough Questionnaire (LCQ) and tested its scaling and clinical properties.
\end{abstract}

Methods: The LCQ was adapted for Dutch conditions following a forward-backward translation procedure. All patients referred to our cough clinic between May 2004 and February 2005 completed five questionnaires, the LCQ, the modified Borg score for cough, the Short-Form 36 (SF-36), the Hospital Anxiety and Depression Scale (HADS) and the Global Rating of Change (GRC) upon presentation, after two weeks and after 6 months. Concurrent validation, internal consistency, repeatability and responsiveness were determined.

Results: For the concurrent validation the correlation coefficients ( $n=152$ patients) between the LCQ and the other outcome measures varied between 0.22 and 0.61 . The internal consistency of the LCQ $(n=58)$ was high for each of the domains with a Crohnbach's alpha coefficient between 0.77 and 0.91 . The two week repeatability of the LCQ in patients with no change in cough $(n=48)$ was high with intraclass correlation coefficients varying between 0.86 and 0.93 . Patients who reported an improvement in cough $(n=140)$ after 6 months demonstrated significant improvement on each of the domains of the LCQ.

Conclusion: The Dutch version of the $L C Q$ is a valid and reliable questionnaire to measure (changes of) health status in patients with chronic cough.

\section{Background}

Chronic cough, defined as cough lasting more than 8 weeks, is a common condition with an estimated prevalence of $20-40 \%[1,2]$. Approximately $10 \%$ of the new patients seen in outpatient clinical settings were referred to the pulmonologist because of cough[3].

Chronic cough can be highly disturbing to the patient and its environment, and determining the cause of cough may 
be difficult. The three most common causes of cough are asthma, gastroesophageal reflux disease and rhinosinusitis. By utilising a systematic protocol for investigation and treatment of cough, it has been reported that in up to 80 to $100 \%$ of patients with cough a cause can be identified and patients can be adequately treated[4].

This "anatomic and diagnostic" protocol relies on the most common causes of cough and has been described more than 25 years ago[5]. We introduced a comparable protocol in May 2004 at our hospital, thus starting the first cough clinic in the Netherlands.

Quality of life is an important outcome parameter in Dutch studies on asthma, COPD, lung cancer and lung transplantation [6-9]. Research on quality of life in patients with chronic cough has been performed only recently [10-12]. However, a quality of life questionnaire in Dutch specific for cough did not exist yet.

Therefore, the aim of this study was to develop a Dutch version of the Leicester Cough Questionnaire (LCQ) and to confirm its reliability, validity and responsiveness.

\section{Methods}

The Leicester Cough Questionnaire (LCQ)

The LCQ is a cough specific quality of life questionnaire with 19 items. It is designed for self-administration and takes less than 5 minutes for completion. The 19 items are divided into 3 domains: physical, psychological and social. A 7-point Likert scale is used to evaluate the answers; a higher score indicates a better health status. The total score is the sum of the scores of the three domains (varying 1 to 7 ). The LCQ already has been validated in English and has also been used in at least one other language[11,13].

\section{Patients}

All patients with chronic cough referred to our tertiary cough clinic between May 2004 and February 2005 were asked to participate by completion of the questionnaires at the first visit, after 2 weeks and after 6 months. Chronic cough was defined as a cough lasting more than 8 weeks that remained unexplained after assessment by the primary care physician.

\section{Questionnaires}

We used the LCQ, the Short Form36 (SF36), a generic quality of life questionnaire[14], the Hospital Anxiety and Depression Scale (HADS), a questionnaire to detect mild forms of depression and anxiety[15], a modified Borg score for cough scoring the intensity on a scale from 0 (no cough at all) to 10 (maximum cough) and a questionnaire to quantify the degree of change in cough (global rating of change: GRC). The GRC assessment was done to evaluate self-perceived changes in disease control since the first visit. Responses were scored from +7 (a very great deal better) to -7 (a very great deal worse); 0 indicated no change. Scores of $-3,-2,+2$ and +3 were considered to represent minimal but nevertheless clinically important changes. [16].

\section{Translation procedure}

The translation followed an established forward-backward translation procedure, with independent translations and counter-translation. Independent translations into Dutch of the LCQ (the authors J.B and A.H) were pooled to a common version. A native English speaker fluent in Dutch and with a medical background translated this provisional Dutch version back into English. This back translation was found to be nearly identical to the source document. The Dutch version [see Additional file] was then tested in 4 patients with chronic cough for problems in acceptance and comprehension of the questionnaire content or the phrasing.

\section{Validation}

To validate the LCQ we tested four different aspects of the questionnaire, i.e. the concurrent validity, the internal consistency, the repeatability and the responsiveness. The first two aspects are related to validity, the instrument's ability to measure what it purports to measure[17]. Concurrent validity was tested by comparing the LCQ with other health outcome questionnaires during the first visit. The internal consistency, the degree of homogeneity within a domain, was determined by the degree of correlation between the answers on the questions within a domain.

The repeatability (or test-retest reliability) measures the stability of scores on the LCQ over time. In our patients repeatability was determined by comparing the LCQ scores of the first visit with the LCQ scores after 2 weeks in patients who reported their cough had been unchanged (GRC score $=0)$.

Responsiveness of a test is the capacity to detect important changes over time[18]. In our study responsiveness was determined by comparing the LCQ scores between the first visit and the LCQ scores after 6 months in patients who told their cough had significantly improved (GRC = 4)

\section{Statistical analysis}

SPSS version 12 was used for data analysis. Data are presented as mean (SE) or ranges. Pearson correlation coefficients between LCQ scores and the scores of the other health outcome were used to determine concurrent validation. Internal consistency was determined by calculating the Cronbach's alpha coefficients for the three 
Table I: Patient characteristics

\begin{tabular}{|c|c|c|}
\hline$n$ & & 152 \\
\hline Sex $m, f(\%)$ & & $50,102(67 \%)$ \\
\hline Age, years & & $59 \pm 12$ \\
\hline Duration of cough, years & & 5.0 \\
\hline FEV , \%predicted & & $103 \pm 21$ \\
\hline \multirow[t]{4}{*}{ LCQ } & physical & $4.4 \pm 1.1$ \\
\hline & psychological & $4.2 \pm 1.0$ \\
\hline & social & $3.8 \pm 1.3$ \\
\hline & total & $12.3 \pm 3.0$ \\
\hline \multirow[t]{2}{*}{ HADS } & anxiety & $4.6 \pm 3.5$ \\
\hline & depression & $4.1 \pm 3.8$ \\
\hline SF-36 & general health & $57.3 \pm 23.2$ \\
\hline Borg cough scale & & $3.6 \pm 1.7$ \\
\hline Current smoker & & $8 \%$ \\
\hline Pack-years (min-max) & & $15(1-100)$ \\
\hline
\end{tabular}

Duration of cough and Pack-years: median value

domains and the total LCQ. Analysis of the test-retest reliability was done by calculating the Intraclass Correlation Coefficient (ICC) for the three domains and for the total score. Responsiveness was analysed by calculating the $95 \%$ confidence interval for the average improvements in the three domain scores and the total score of the LCQ.

\section{Results}

\section{Patients}

The patients' characteristics are shown in table 1. The majority of the patients were female, of middle age.

\section{Concurrent validity}

The correlation coefficients of the concurrent validity, determined in 152 patients, are shown in table 2. Except for two all outcome are statistically significant. Summarised, the correlation coefficients with the Borg Cough Scale, the SF-36 general health and the HAD total score were respectively $-0.41,0.41$ and -0.46 .

Internal consistency

The Cronbach's alpha coefficients for the physical, psychological, social domains and for the total questionnaire

Table 2: Concurrent validity

\begin{tabular}{|c|c|c|c|c|}
\hline Validated outcome scales & LCQ physical & LCQ psychological & LCQ social & LCQ total \\
\hline Borg cough scale & -0.37 & -0.38 & -0.36 & -0.41 \\
\hline HADS anxiety & -0.41 & -0.40 & -0.33 & -0.43 \\
\hline HADS depression & -0.36 & -0.36 & -0.38 & -0.42 \\
\hline HADS total & -0.42 & -0.42 & -0.39 & -0.46 \\
\hline SF-36 general health & 0.54 & 0.28 & 0.30 & 0.41 \\
\hline SF-36 vitality & 0.61 & 0.38 & 0.45 & 0.55 \\
\hline SF-36 mental & 0.39 & 0.41 & 0.39 & 0.45 \\
\hline SF-36 pain & 0.46 & 0.22 & 0.28 & 0.36 \\
\hline SF-36 emotional & 0.35 & 0.32 & 0.16 (NS) & 0.30 \\
\hline SF-36 physical & 0.49 & 0.23 & 0.29 & 0.37 \\
\hline SF-36 social functioning & 0.50 & 0.38 & 0.43 & 0.50 \\
\hline SF-36 physical functioning & 0.50 & 0.24 & 0.34 & 0.40 \\
\hline SF-36 health changes & 0.11 (NS) & 0.22 & 0.22 & 0.22 \\
\hline
\end{tabular}

Pearson's correlation coefficients between scores on validated questionnaires (Borg cough scale, SF-36, and HADS) and the domain scores and the total score of the LCQ. All correlation coefficients $p<0.05$, unless otherwise described. 
Table 3: Repeatability

\begin{tabular}{|c|c|c|c|c|}
\hline \multirow[t]{2}{*}{ Domain LCQ } & \multicolumn{2}{|c|}{ Intraclass correlation coefficient } & \multirow[t]{2}{*}{$95 \% \mathrm{Cl}$} & \multirow[t]{2}{*}{ p-value } \\
\hline & Birring [II] & Zwolle & & \\
\hline Physical & 0.93 & 0.86 & $0.76-0.92$ & $<0.0001$ \\
\hline Psychological & 0.90 & 0.93 & $0.88-0.96$ & \\
\hline Social & 0.88 & 0.93 & $0.87-0.96$ & \\
\hline Total & 0.96 & 0.93 & $0.87-0.96$ & \\
\hline
\end{tabular}

Results of the test-retest reliability analysis. The Intraclass correlation coefficients (ICC) are depicted separately for every domain and for the total questionnaire with the suitable $95 \%$ confidence interval $(95 \% \mathrm{Cl})$.

were $0.77,0.84,0.83$ and 0.93 respectively. A Cronbach's alpha coefficient $>0.7$ is generally accepted as good.

\section{Test-retest reliability}

The intraclass correlation coefficient (ICC) of the testretest reliability was 0.93 for the total score. In table 3 the ICCs are shown for the domains and the total score. In addition, the results of the original LCQ are shown.

\section{Responsiveness}

The LCQ scores improved significantly after treatment. Results are shown in table 4.

\section{Discussion}

Our results show that the Dutch version of the LCQ [see Additional file 1] is a valid and reliable instrument to measure quality of life in patients with chronic cough. The relationship between the Dutch LCQ and other QOL parameters was moderate. This is expected when the LCQ is compared against generic tools not specific for cough. The LCQ appears to be highly repeatable and responsive to change and therefore can be used to evaluate the results of interventions of cough clinics. The Dutch version allows us to compare our patients and outcomes to other clinics using the LCQ.

Quality of life can also be measured by another cough specific questionnaire, the cough quality-of-life questionnaire (CQLQ)[10]. The CQLQ comprises 28 items and 6 domains; the answers are scored on a 4-point Likert scale. A higher score indicates a worse quality of life due to cough. The LCQ as well as the CQLQ are both designed for self-administration. Both questionnaires have been compared in one study where they showed a good corre- lation[13]. In this particular study, no details were provided about the translation procedure or the validation of the Turkish versions.

Quality of life is a subjective parameter. Objective measurement of cough using a 24-hour registration of cough sounds has been reported[19]. This method has not been validated yet. Psychological and social consequences of chronic cough seem to matter more for patients than physical consequences[12]. Therefore we consider the LCQ, a health status measure at the moment as the most important parameter to evaluate chronic cough. It perfectly fits to the patient's perception and there is lack of well-validated reliable objective alternative parameters that are commercially available to quantify the burden of chronic cough.

\section{Conclusion}

In conclusion, the Dutch version of the LCQ is a brief, easy to administer questionnaire and appears to be valid, reliable and highly responsive.

\section{Competing interests}

The author(s) declare that they have no competing interests.

\section{Authors' contributions}

$\mathrm{AH}$ and MW participated in the design of the study and helped to draft the manuscript. SU participated in the design of the study and performed the statistical analysis. JB conceived of the study, participated in the design and coordination and drafted the manuscript. All authors read and approved of the final manuscript.

Table 4: Responsiveness

\begin{tabular}{lcc}
\hline Domain LCQ & Improvement score & $\mathbf{9 5 \% C l}$ \\
\hline Physical & 1.42 & $1.14-1.71$ \\
Psychological & 1.77 & $1.47-2.06$ \\
Social & 2.10 & $1.70-2.49$ \\
Total & 5.28 & $4.41-6.15$
\end{tabular}

Results of the responsiveness analysis. The average improvements after 6 months in the domain scores and for the total score of the LCQ are depicted with $95 \%$ confidence interval 


\section{Copyright}

Reprints of questionnaire: the Leicester Cough Questionnaire including the Dutch version is protected by copyright. Reprints are available from corresponding author and that of Ref 11 .

\section{Additional material}

\section{Additional File 1}

The Dutch version of the Leicester Cough Questionnaire. This questionnaire (in Dutch) is the translation of the Leicester Cough Questionnaire. Click here for file

[http://www.biomedcentral.com/content/supplementary/17459974-3-3-S1.doc]

\section{References}

I. Fuller RW, Jackson DM: Physiology and treatment of cough. Thorax 1990, 45:425-430.

2. Cullinan P: Persistent cough and sputum: prevalence and clinical characteristics in south east England. Respir Med 1992, 86:143-149.

3. Brightling CE, WARD RICH, GOH KAHLAY, WARDLAW ANDREW], Pavord ID: Eosinophilic Bronchitis Is an Important Cause of Chronic Cough. Am J Respir Crit Care Med 1999, 160:406-410.

4. Morice $\mathrm{AH}$, Committee $\mathrm{M}$ : The diagnosis and management of chronic cough. Eur Respir J 2004, 24:48I-492.

5. Irwin RS, Corrao WM, Pratter MR: Chronic persistent cough in the adult: the spectrum and frequency of causes and successful outcome of specific therapy. Am Rev Respir Dis I98I, | 23:4|3-4|7.

6. Rutten-van Molken MP, Custers F, van Doorslaer EK, Jansen CC, Heurman L, Maesen FP, Smeets JJ, Bommer AM, Raaijmakers JA: Comparison of performance of four instruments in evaluating the effects of salmeterol on asthma quality of life. European Respiratory Journal 1995, 8:888-898.

7. Oostenbrink JB, Rutten-van Molken MPMH, AI MJ, van Noord JA Vincken W: One-year cost-effectiveness of tiotropium versus ipratropium to treat chronic obstructive pulmonary disease. European Respiratory Journal 2004, 23:24I-249.

8. Wachters FM, Van Putten JW, Kramer H, Erjavec Z, Eppinga P, Strijbos JH, de Leede GP, Boezen HM, de Vries EG, Groen HJ: First-line gemcitabine with cisplatin or epirubicin in advanced nonsmall-cell lung cancer: a phase III trial. Br J Cancer 2003, 89: $1192-1199$

9. van den Berg JW, Geertsma A, van Der BJ], Koeter GH, de Boer WJ, Postma DS, Ten Vergert EM: Bronchiolitis Obliterans Syndrome after Lung Transplantation and Health- related Quality of Life. Am J Respir Crit Care Med 2000, 161:1937-194I.

10. French CT, Irwin RS, Fletcher KE, Adams TM: Evaluation of a Cough-Specific Quality-of-Life Questionnaire*. Chest 2002, I 21:II|23-II3I.

II. Birring SS, Prudon B, Carr AJ, Singh SJ, Morgan MDL, Pavord ID: Development of a symptom specific health status measure for patients with chronic cough: Leicester Cough Questionnaire (LCQ). Thorax 2003, 58:339-343.

12. French CL, Irwin RS, Curley F], Krikorian CJ: Impact of Chronic Cough on Quality of Life. Archives of Internal Medicine 1998 | 58: $|657-| 66 \mid$.

13. Kalpaklioglu AF, Kara T, Kurtipek E, Kocyigit P, Ekici A, Ekici M: Evaluation and impact of chronic cough: comparison of specific vs generic quality-of-life questionnaires. Ann Allergy Asthma Immunol 2005, 94:58I-585.

14. Brazier JE, Harper R, Jones NM, O'Cathain A, Thomas KJ, Usherwood $T$, Westlake L: Validating the SF-36 health survey questionnaire: new outcome measure for primary care. BMJ 1992, 305: 160-164.
15. Bjelland I, Dahl AA, Haug TT, Neckelmann D: The validity of the Hospital Anxiety and Depression Scale. An updated literature review. J Psychosom Res 2002, 52:69-77.

16. Kocks JW, Tuinenga MG, Uil SM, van den Berg JW, Stahl E, Van Der MT: Health status measurement in COPD: the minimal clinically important difference of the Clinical COPD Questionnaire. Respir Res 2006, 7:62.

17. Lohr KN, Aaronson NK, Alonso J, Burnam MA, Patrick DL, Perrin EB, Roberts JS: Evaluating quality-of-life and health status instruments: development of scientific review criteria. Clin Ther 1996, 18:979-992.

18. Testa MA, Simonson DC: Assesment of quality-of-life outcomes. N Engl J Med 1996, 334:835-840.

19. Smith J, Owen E, Earis J, Woodcock A: Effect of codeine on objective measurement of cough in chronic obstructive pulmonary disease. J Allergy Clin Immunol 2006, I I 7:83 I-835.
Publish with Bio Med Central and every scientist can read your work free of charge

"BioMed Central will be the most significant development for disseminating the results of biomedical research in our lifetime. "

Sir Paul Nurse, Cancer Research UK

Your research papers will be:

- available free of charge to the entire biomedical community

- peer reviewed and published immediately upon acceptance

- cited in PubMed and archived on PubMed Central

- yours - you keep the copyright 